\title{
Revisando a Inserção Ecológica: Uma Proposta de Sistematização
}

\author{
Revisiting the Ecological Engagement: A Proposal to Systematization \\ Laíssa Eschiletti Prati, Maria Clara P. de Paula Couto, Andreína Moura, \\ Michele Poletto \& Sílvia H. Koller* \\ Universidade Federal do Rio Grande do Sul, Porto Alegre, Brasil
}

\begin{abstract}
Resumo
O presente artigo descreve como os quatro conceitos-chave da Teoria Bioecológica do Desenvolvimeno Humano (processo, pessoa, contexto e tempo) se fazem presentes na metodologia denominada Inserção Ecológica. Tem o objetivo de proporcionar algumas linhas de ação que podem auxiliar equipes de pesquisa na utilização desta proposta em seus projetos de pesquisa. Para isso, foi realizada uma breve comparação entre a Inserção Ecológica e outras metodologias que valorizam o contex to da investigação, e que partem de referenciais teóricos diferentes. Além disso, são apresentados e discutidos estudos que utilizaram a Inserção Ecológia a fim de estabelecer alguns pontos em comum e definir aspectos que possam ser considerados características fundamentais a essa proposta metodológica.

Palavras-chave: Método; desenvolvimento humano; modelo teórico-metodológico.
\end{abstract}

\begin{abstract}
This article describes how the four key concepts of the Bioecological Theory of Human Development (process, person, context and time) are present in the Ecological Engagement methodology. The goal is to provide some lines of action that may guide research teams to use this proposal in their projects. A brief comparison is performed between the Ecological Engagement and other methodologies, which value the concept of investigation and have distinct theoretical references. Moreover, other studies that used the Ecological Engagement are presented and discussed in order to establish some common points and to define aspects that may be considered as fundamental characteristics of this methodological proposal.

Keywords: Method; human development; theoretic-methodological model.
\end{abstract}

A Teoria Bioecológica do Desenvolvimento Humano (TBDH) foi constantemente reformulada e reestruturada devido ao olhar crítico de seu principal teórico, Urie Bronfenbrenner, bem como dos seus colaboradores. Ela destaca a importância e a influência dos ambientes ecológicos no desenvolvimento humano. A análise destes âmbitos de interação possibilita o acesso às oportunidades de crescimento, aos momentos de estabilidade e instabilidade dos contextos nos quais as pessoas estão inseridas, as interações afetivas e as relações de poder na dinâmica interpessoal (Bronfenbrenner, 1979/1996). Com a evolução da teoria, os seus conceitos principais foram sendo revisados quanto a sua importância na compreensão do desenvolvimento humano.

O primeiro modelo teórico delineado por Bronfenbrenner (1979/1996) tinha no ambiente seu foco principal. $\mathrm{O}$ contexto em que o indivíduo estava inserido e a forma como ele o percebia, mais do que como ele se configurava objetivamente, era fundamental para compreender o desen-

\footnotetext{
* Endereço para correspondência: Universidade Federal do Rio Grande do Sul, Instituto de Psicologia, PPG Psicologia. Av. Ramiro Barcelos, 2600, sala 104, Santana, Porto Alegre, RS, 90035-003. Caixa-Postal: 9001. Tel.: (51)3308 5150; Fax: (51)3241 1328. E-mail: silvia.koller@pesquisador.cnpq.br
}

volvimento. Em 1992, Bronfenbrenner denominou suas proposições de Teoria dos Sistemas Ecológicos e contemplou de forma mais detalhada os aspectos do desenvolvimento vinculados à pessoa. A evolução da teoria gerou uma ampliação do entendimento do desenvolvimento de forma a considerar quatro aspectos interrelacionados: o processo, a pessoa, o contexto e o tempo (modelo PPCT). As alterações deste modelo, levaram ao Modelo Bioecológico de Desenvolvimento Humano e, atualmente, à Teoria Bioecológica do Desenvolvimento Humano. Um dos principais conceitos, que ganha importância na evolução das idéias de Bronfenbrenner, é o de processo proximal, considerado o primeiro mecanismo produtor de desenvolvimento humano (Copetti \& Krebs, 2004).

No entanto, apesar das inúmeras mudanças realizadas na teoria, Bronfenbrenner nunca propôs um método de pesquisa claramente operacionalizado. Sabe-se que, para adotar um modelo de pesquisa baseado nesta teoria, os pesquisadores devem construir seu delineamento e sua análise a partir de seus quatro elementos-chave (modelo PPCT). Mas as formas através das quais esses âmbitos afetam os delineamentos de pesquisa não são muito exploradas. São feitas descrições de pesquisas que se aproximam da proposta da teoria (Bronfenbrenner, 1999, 2005; Bronfenbrenner \& Evans, 2000), mas não é construído um 
método para ser utilizado pelos pesquisadores que se apóiam na TBDH.

Como teoria e métodos se entrelaçam, novas sistematizações foram surgindo, desenvolvidas por grupos que adotam essa abordagem, visando ao melhor acesso aos sistemas de desenvolvimento humano. No Brasil, após a execução de algumas pesquisas baseadas neste modelo, surgiu a proposta metodológica denominada Inserção Ecológica, que será revisada neste texto (Cecconello \& Koller, 2003). Portanto, o presente ar tigo pretende descrever como os quatro conceitos-chave da TBDH (processo, pessoa, contexto e tempo) se fazem presentes na Inserção Ecológica. Serão apresentados e discutidos alguns estudos (Cecconello, 2003; De Antoni, 2005; Morais, 2005; NeivaSilva, 2003) que utilizaram esse método de investigação. Nem todas as pesquisas que têm como suporte teórico a TBDH utilizam a Inserção Ecológica como sistematização do modelo PPCT. Esta é uma opção de alguns pesquisadores, influenciados pelo problema de pesquisa a ser investigado. Sendo assim, introduz-se algumas linhas de ação para auxiliar equipes de pesquisa que pretendem utilizar esse referencial teórico através da Inserção Ecológica.

\section{A Inserção Ecológica e o Modelo PPCT}

A Inserção Ecológica, proposta metodológica desenvolvida por Cecconello e Koller (2003), envolve a sistematização dos quatro aspectos do modelo PPCT pela equipe de pesquisa. Este método tem como objetivo avaliar os processos de interação das pessoas com o contexto no qual estão se desenvolvendo. Surge como uma alternativa àqueles estudos psicológicos que enfatizam apenas as características dos indivíduos, sem valorizar o contexto, ou sendo mais específico, sem apreender o processo de desenvolvimento. $\mathrm{O}$ ambiente neste tipo de investigação tem, portanto, papel chave, já que é nele que as interações e os processos proximais acontecem (entre pessoas, objetos e símbolos). A seguir serão brevemente apresentados os elementos do modelo PPCT e como estes se articulam com a proposta da Inserção Ecológica.

\section{Processo}

O desenvolvimento humano acontece quando se estabelece um padrão de interação estável e recíproco entre pessoas e seus ambientes. Segundo Bronfenbrenner (2005):

Ao longo do curso de vida, o desenvolvimento humano acontece através de processos de interações recíprocas progressivamente mais complexas entre um organismo humano ativo, em evolução biopsicológica, e pessoas, objetos e símbolos no seu ambiente externo imediato. Para ser efetiva, a interação deve ocorrer numa base consideravelmente regular, através de longos períodos de tempo. Tais formas duradouras de interação no ambiente imediato são definidas como processos proximais. Exemplos desses processos incluem alimentar e confortar um bebê; brincar com uma criança pequena; atividades entre crianças; jogos em grupo ou solitários; leitura e aprendizagem de novas habilidades; atividades atléticas; resolução de problemas; cuidado por outros; fazer planos; realizar tarefas complexas e adquirir novos conhecimentos . . . Em resumo, processos proximais posicionam-se como motores primários do desenvolvimento. (p. 6).

O processo proximal, segundo Bronfenbrenner e Ceci (1994), é necessário para o desenvolvimento das capacidades biológicas e do potencial genético de cada pessoa, pois possibilita que os recursos pessoais sejam estimulados e desenvolvidos. Bronfenbrenner (1999) sublinhou a importância da presença simultânea de cinco aspectos para que se estabeleça um processo proximal: (a) a pessoa deve estar engajada em uma atividade; (b) esta atividade deve acontecer em uma base relativamente regular, através de períodos estendidos de tempo; (c) as atividades devem ser progressivamente mais complexas; (d) deve haver reciprocidade nas relações interpessoais; e, (e) os objetos e símbolos presentes no ambiente imediato devem estimular a atenção, exploração, manipulação e imaginação da pessoa em desenvolvimento.

Cecconnello e Koller (2003) defendem que o processo proximal surge através da interação recíproca, complexa e com base regular de pesquisadores, participantes, objetos e símbolos presentes no contexto imediato, constituindo a base de toda investigação que adota a Inserção Ecológica. O processo proximal, além de ser o foco da investigação, é o que permite o desenvolvimento da pesquisa. O processo de investigação-no-contexto, como o proposto pela Inserção Ecológica, envolve o compartilhamento de informações, percepções e sentimentos dentro da equipe, na qual as experiências individuais e os aspectos observados no ambiente são comunicados. Desta forma, o processo de pesquisa também gera processos proximais no desenvolvimento da própria equipe.

A proposta apresentada por Cecconnello e Koller (2003) apresenta uma ampliação do conceito de processos proximais. Não somente as pessoas se desenvolvem naquele contexto específico, mas o pesquisador (que se insere diretamente nesse contexto) passa a ter o seu próprio desenvolvimento alterado. Em alguns casos é impossível estabelecer os resultados dessa interação no contexto em estudo, mas a importância da presença da equipe de pesquisa em um contexto, de forma séria e comprometida, gera a troca de informações e energia, estabelecendo, portanto, processos proximais.

\section{Pessoa}

O ser humano, descrito por Bronfenbrenner (2005) como um ser biológico e psicológico, interage constantemente com seu contexto e é produto deste processo de interação. Bronfenbrenner usou o termo interação com uma conotação espiral, multicausal e processual. Ou seja, o desenvolvimento humano ocorre através de ampliações e aproximações entre a pessoa e os diversos elementos do contexto que se influenciam mutuamente de forma não linear e dinâmica, alterando-se qualitativamente ao longo do tempo. Interação relaciona-se com o estudo de processos e relações entre variáveis que estão em constante alte- 
ração, e não com elementos isolados. Salientou que interações ocorrem com pessoas, mas também delas com símbolos e seus contextos (Bronfenbrenner \& Morris, 1998). Interação significa mais que uma relação simples e pontual, porque implica alterações em ambas as partes envolvidas. É como se a pessoa se desenvolvesse em “inter-ação”, no inter-jogo, em constante troca com os outros e com o ambiente. $\mathrm{Na}$ interação a pessoa constrói sentidos que definem a sua forma particular de ação nos diversos contextos de desenvolvimento.

Desde sua primeira formulação teórica, Bronfenbrenner (1979/1996) mencionou a presença da reciprocidade nas relações, abarcando todas as direções. Ou seja, o que A faz influencia B e, também, altera a si mesmo (A) reciprocamente. As ações de $\mathrm{C}$, que pode ser um mero observador ao mesmo tempo em que sofre influências dos outros elementos (A e B), também os modifica. Um elemento é, simultaneamente, influenciado e exerce influência sobre o comportamento dos demais, formando um emaranhado de relações. Em qualquer relação e, especialmente, no curso de uma atividade conjunta, há reflexos e feedbacks mútuos entre as pessoas que, conseqüentemente, produzem efeitos desenvolvimentais sobre o ciclo vital de todos os envolvidos. A reciprocidade gera um momentum próprio, que estimula e mobiliza as pessoas a se engajarem e a perseverarem em padrões de interação progressivamente mais complexos. Quanto maior a reciprocidade na interação maior a complexidade da mesma.

$\mathrm{Na}$ Inserção Ecológica, o pesquisador é valorizado de forma semelhante ao participante da pesquisa. Cada um tem seus processos de interação alterados, proporcionando a construção de um campo comum de desenvolvimento. A equipe de pesquisa, inserida no contexto em estudo, estabelece relações de reciprocidade que são valorizadas e consideradas na compreensão dos dados e sistematização dos resultados.

\section{Contexto}

$\mathrm{Na} \mathrm{TBDH}$, a influência do ambiente no processo de desenvolvimento difere entre as pessoas em termos de extensão e quanto ao tipo de conseqüências. $\mathrm{O}$ ambiente tem papel decisivo no desenvolvimento, sendo compreendido em termos físicos, sociais e culturais. Da mesma forma, a percepção psicológica do ambiente pela pessoa influencia a forma como cada uma se desenvolverá. Esta compreensão supera uma relação linear entre contexto e pessoa, na qual apenas um influencia o outro, que tem sido perpassada em diversas teorias do desenvolvimento humano. A relação entre pessoa e ambiente é multidirecional, com ambos os elementos se interinfluenciando. $\mathrm{O}$ ambiente não é concebido simplesmente como uma fonte de estimulações que elicia respostas independentes, pois o indivíduo tem um papel ativo e intencional, não se constituindo como elemento isolado. O contexto atua como uma fonte de informações com a qual a pessoa interage em vários níveis de complexidade (Magnusson, 1995).

O contexto, portanto, foi subdividido em quatro níveis de interação o microssistema, mesossistema, exossistema e macrossistema (Bronfenbrenner, 1979/1996). É necessário que a Inserção Ecológica ocorra nos microssistemas (onde acontecem os processos proximais) e que sua compreensão possa ser relacionada com os demais sistemas, ampliando o campo de investigação. Por exemplo, uma investigação no contexto escolar pode ter como foco de estudo: as relações em sala de aula (microssistema), as relações entre professores e as famílias dos estudantes (mesossistema), as reuniões de coordenação dos diretores com os professores (exossistema), ou ainda, a compreensão da cultura na qual está inserida a escola (macrossistema). É fundamental que os pesquisadores tenham clareza de seus objetivos para elaborar um programa de trabalho que permita o acesso aos sistemas mais adequados. Para cada investigação, dependendo dos objetivos, os pesquisadores delimitarão seu foco de estudo e elegerão o contexto mais apropriado para a análise almejada. Por ser a psicologia do desenvolvimento um campo recente, existem inúmeras áreas pouco estudadas sob o foco da TBDH. Por exemplo, o desenvolvimento do adulto em interação com sua família de origem ou, ainda, o desenvolvimento do idoso em situações de atividades em grupos sociais ou sua relação com algumas limitações desse momento do ciclo vital são campos ainda pouco explorados. No entanto, o foco de investigação estará direcionado às interações que essas pessoas estabelecem em um ou mais contextos específicos. Mesmo focando um ou outro sistema, os pesquisadores não devem perder de vista a existência dos outros, que interagem e influenciam o desenvolvimento de todos os envolvidos.

\section{Tempo}

Ao salientar que o desenvolvimento ocorre através de processos proximais, Bronfenbrenner (1986) deparou-se com a questão do tempo e sua influência natural no desenvolvimento humano. Estruturou, então, o conceito de cronossistema, estabelecendo um modelo de pesquisa que possibilita examinar as influências no desenvolvimento da pessoa e as mudanças (e continuidades) ao longo do tempo no ambiente no qual a pessoa vive. Esse conceito reforça a idéia do envolvimento interconectado da pessoa em seu contexto com os processos ao longo do tempo. Tal inclusão indica o reconhecimento da mudança constante e da impossibilidade de desenvolvimento sem o estabelecimento de processos interacionais. O tempo exerce um papel no desenvolvimento, a partir de transformações e continuidades características do ciclo vital. As interações ocorridas no cronossistema exercem uma influência cumulativa nos processos significativos de desenvolvimento humano.

Ao acompanhar o ciclo de desenvolvimento de um ser humano, é visível que o impacto desenvolvimental das pessoas em interação se altera ao longo dos anos. A complexidade aumenta em relação direta com o nível de reciprocidade, complexidade, mutualidade do sentimento positivo e de uma gradativa modificação do equilíbrio do poder em favor da pessoa em desenvolvimento. A interação recíproca torna-se um meio com momentos únicos, que motivam e servem de suporte para os processos desenvol- 
vimentais. Tal fenômeno ocorre à medida que as pessoas permanecem em interação (Bronfenbrenner \& Morris, 1998). O tempo, portanto, é um elemento fundamental na análise e constituição de processos proximais. A realização de uma pesquisa que adota a Inserção Ecológica, portanto, exige que os pesquisadores trabalhem, ao longo do tempo, considerando as alterações no desenvolvimento de todos os envolvidos no processo de pesquisa (sejam participantes ou pesquisadores). As interações que se estabelecem neste processo influenciam o desenvolvimento de todos.

Antes de explorar as características específicas da Inserção Ecológica, é importante salientar que existem outros métodos que também trabalham com a inserção de pesquisadores no campo de investigação. Estes se preocupam com a relação dos pesquisadores com o campo. Entre eles, destacam-se a observação participante, a pesquisa participante e a etnografia. As principais diferenças entre essas abordagens e a Inserção Ecológica é o foco no desenvolvimento humano a partir dos quatro elementos da Teoria Bioecológica.

A Inserção Ecológica, ao mesmo tempo, apresenta algumas similaridades com esses outros métodos. Todas as abordagens enfatizam a necessidade de envolvimento com o campo e de considerar a subjetividade no contexto investigado. Entretanto, a base teórica na qual se apóiam e a intenção dos pesquisadores em uma e em outra abordagem indicam as principais diferenças entre os métodos. A Inserção Ecológica está apoiada nos preceitos da TBDH, postulada por Bronfenbrenner (1979/1996), que repercute nos objetivos dos pesquisadores. Enquanto a pesquisa participante tem como objetivo devolver ao grupo aspectos identificados em seu funcionamento e estrutura, os pesquisadores ecológicos estão preocupados em compreender o processo de desenvolvimento das pessoas. Ou seja, pretendem investigar as relações (processos) que elas estabelecem durante seu crescimento pessoal ou social, no curso de sua história (tempo) em um determinado contexto. Os pesquisadores, e aí se encontra uma importante diferença, além de não serem neutros, têm seu próprio processo pessoal de desenvolvimento influenciado pelas interações que estabelecem com os participantes da pesquisa. Os pesquisadores ecológicos são pessoas em desenvolvimento (processo), fazendo parte do cenário da pesquisa (contexto), em um momento de sua história pessoal (tempo). A TBDH permite compreender os processos que se estabelecem no desenvolvimento humano enquanto a pesquisa se realiza. Uma compreensão que envolve desde o relacionamento entre duas pessoas até al terações no contexto cultural mais amplo no qual essas se encontram. É uma visão dinâmica e complexa que enfatiza e permite o acesso à instabilidade e à mudança sempre presente no desenvolvimento humano.

A TBDH salienta que tanto as pessoas como seus ambientes estão em constante alteração (Elder, 1995). O desenvolvimento ocorre através das relações que se estabelecem entre a pessoa em desenvolvimento e o ambiente em mudança. Como enfatizam Cairns e Cairns (1995), "no curso de desenvolvimento, os indivíduos inevitavelmente crescem, amadurecem e mudam. Ao mesmo tempo, mudanças ocorrem em suas sociedades, comunidades e rede social” (p. 399). Essa relação entre pessoa e ambiente possui um caráter processual, pois na medida em que a pessoa muda seu entorno, este também se modifica. Quando o ambiente se altera, as pessoas, conseqüentemente, se transformam, havendo uma relação espiralada entre estes elementos.

O envolvimento com o contexto por parte de todos os membros da equipe de pesquisa é condição prévia à Inserção Ecológica. Há uma busca pela compreensão dos espaços estudados, através do rastreamento das interações que acontecem entre os diversos sujeitos, símbolos e objetos do contexto e que possibilitarão a validade ecológica dos achados. O nível de inserção está intimamente ligado ao problema de pesquisa. Assim, os pesquisadores vão a campo observar e coletar diversos dados, mesmo os que não se relacionam ao seu tema de pesquisa, para melhor entender o processo, a pessoa, o contexto e o tempo no desenvolvimento humano. Esta inserção, ainda que informal, precisa abarcar a complexização da interação e o rigor dos dados colhidos e registrados sistematicamente. É necessário, portanto, que os objetivos da pesquisa sejam claros, para que os dados coletados sejam filtrados e eleitos a fim de responderem a estes.

Para que fique clara a importância do contexto na Teoria Bioecológica do Desenvolvimento Humano, é necessário retomar o conceito de processo proximal. Segundo Bronfenbrenner (2005), o desenvolvimento humano acontece através de interações recíprocas progressivamente mais complexas entre um ser biopsicológico e pessoas, objetos e símbolos de seu ambiente mais imediato. Percebe-se que o ambiente mais imediato tem um papel central na teoria desenvolvida por Bronfenbrenner, pois são os recursos que estão contidos nele que possibilitam o desenvolvimento. Contudo, Bronfenbrenner enfatiza que o ambiente mais amplo influencia diretamente a forma como os recursos do ambiente imediato estão organizados. Além disso, os resultados desenvolvimentais estabelecidos através dos processos proximais surgem em função não apenas do ambiente, mas das características da pessoa (incluindo as genéticas). A partir destas proposições, nota-se que há, como já foi dito, uma relação multidirecional entre pessoa e ambiente.

A Inserção Ecológica, conforme descrita em Cecconello e Koller (2003), apoia-se nos cinco aspectos indispensáveis para o estabelecimento de processos proximais. Sendo assim, (a) pesquisadores e participantes interagem e se engajam em uma tarefa comum; (b) há a necessidade de diversos encontros, ao longo de um considerável período de tempo; (c) encontros informais progredirão para conversas que devem abordar temas cada vez mais complexos, chegando a ter a duração igual ou superior a uma hora; (d) os processos proximais que se estabelecem nesses encontros servem de base para todo o processo de pesquisa, sendo fundamental a postura de informalidade e conversa nos mesmos, possibilitando o diálogo sobre pon- 
tos não diretamente relacionados ao objetivo do estudo; e (e) os temas abordados nas entrevistas são interessantes e estimulantes para os pesquisadores e para os participantes, pois exploravam as histórias de vida e a forma como se dá o desenvolvimento inserido no contexto em estudo.

Nos exemplos de processos proximais, apresentados por Bronfenbrenner (2005), torna-se evidente a necessidade de constância e regularidade de tempo para que o curso do desenvolvimento saudável (ou não) se estabeleça. São citados como exemplos de processos proximais as interações entre pais e filhos, professores e alunos, avós e netos, irmãos ou amigos, colegas de trabalho e vizinhos. Ambos protagonistas são recursivamente importantes um para o desenvolvimento do outro. Na Inserção Ecológica, é difícil precisar quais os efeitos exatos sobre o desenvolvimento obtidos durante uma pesquisa. No entanto, processos proximais certamente se estabelecem entre pesquisadores e participantes, pesquisadores e outros membros da equipe, pesquisadores e instituições nas quais a investigação se desenvolve.

O processo proximal é estabelecido quando todas as pessoas que atuam nesse inter-jogo se desenvolvem, sendo por isso considerado um processo recíproco. Durante a execução de uma pesquisa que adota a Inserção Ecológica, por exemplo, reciprocidade implica troca e esta se estabelece de diversas formas entre os pesquisadores e os participantes. Desde o início da pesquisa, os participantes têm em mente que essa troca acontecerá, já que a participação é voluntária e há uma preocupação em apresentar claramente os objetivos do estudo.

A inserção-no-contexto deve ser previamente contratada. O contrato não acontece por acaso, mas deve ser fruto de planejamento e reflexão. Os pesquisadores precisam deixar bem claro aos participantes quais serão as atividades, o tempo, a necessidade de envolvimento, riscos e conseqüências da pesquisa, assim como a devolução que será feita dos dados encontrados. O tempo de duração do trabalho também deve ser combinado entre as partes, garantindo que as expectativas de ambos protagonistas serão limitadas em duração. É fundamental que os participantes saibam quando começa e quando termina o processo de pesquisa, com suas etapas e momentos bem definidos. Tal contrato permite o estabelecimento de relações saudáveis durante e depois da investigação. O Termo de Consentimento Livre e Esclarecido pode ser um bom instrumento de contrato entre as partes.

O Termo de Consentimento Livre e Esclarecido (TCLE) é uma maneira de formalizar a reciprocidade na relação participante-pesquisador(a), pois este documento descreve todos os direitos e deveres das partes envolvidas na pesquisa. A obrigatoriedade do uso deste documento em pesquisas que envolvem seres humanos foi definida pelo Conselho Nacional de Saúde em sua Resolução número 196/96. Esta Resolução determina que todo e qualquer pesquisador(a) que pretenda envolver seres humanos em seu estudo deve obter o consentimento do participante e/ ou de seu representante legal, através da assinatura de um documento. Há a determinação que os pesquisadores não devem utilizar simulação, fraude ou erro, dependência, subordinação ou intimidação para conseguir tal consentimento. Os pesquisadores devem explicar por completo a natureza da pesquisa, seus objetivos, métodos, benefícios previstos, potenciais riscos e quaisquer incômodos que esta possa ocasionar. Ao elaborar o TCLE, os pesquisadores devem considerar todos estes princípios, garantindo que os procedimentos da pesquisa estejam dentro dos padrões éticos, esclarecendo aos participantes que a participação é inteiramente voluntária. Assim, quando o participante assina o TCLE, tem como prerrogativa que fornece sua anuência sobre a participação na pesquisa, concordando com os procedimentos. Pesquisadores e participantes estabelecem um contrato de reciprocidade no qual têm ciência sobre como a relação entre eles irá proceder, deixando claro que ambas as partes concordam. Os pesquisadores que utilizam a Inserção Ecológica ao usar este documento em suas pesquisas garantem que os participantes serão protegidos legalmente. Isto dá aos participantes uma maior segurança para se engajarem nas relações, facilitando as trocas e ampliando a reciprocidade na relação. Contudo, apesar de o TCLE servir como uma espécie de contrato inicial para a realização da pesquisa, é necessário que os pesquisadores na Inserção Ecológica se engajem além das formalidades descritas nele. É imprescindível que eles estejam dispostos a se integrar no contexto, se relacionando da maneira adequada, comprometida, ética e mais próxima possível dos participantes.

A duração da inserção dos pesquisadores no campo está intimamente ligada ao objetivo do estudo. Nesse sentido, o timing (entendido como o momento ótimo para o início formal da pesquisa) da Inserção Ecológica é definido de acordo com o objetivo, o foco a ser investigado pela equipe de pesquisa, e formalizado através do TCLE dos participantes. O timing da inserção influencia tanto no desenvolvimento humano quanto no desenvolvimento da pesquisa. Para uma interação gerar um efeito duradouro no desenvolvimento é preciso que aconteça em um momento ótimo. Podem surgir situações de crise (ou stress) que desencadeiam a retomada de recursos ou a tentativa de reorganização de sua evolução. Na Inserção Ecológica, os objetivos da pesquisa definem o momento de ingresso e de saída da equipe no campo e a forma como as interações se estabelecem.

Há ainda a necessidade de que os participantes considerem que a pesquisa é importante para o seu desenvolvimento. A pesquisa deve ser vista como uma oportunidade e não como uma imposição. Trabalhar com um contexto não favorável impede o estabelecimento de processos proximais, prejudicando o andamento da pesquisa. Por haver uma preocupação em estabelecer um processo de interação rico entre pesquisadores e participantes é fundamental a reciprocidade de interesse no desenvolvimento do estudo.

Entretanto, conforme os objetivos do estudo, o timing da Inserção Ecológica deve ser bastante planejado. Por exemplo, se a intenção é verificar qual a atitude das crianças no cotidiano familiar, durante o período de adaptação 
escolar, é importante acompanhar este cotidiano alguns meses antes do ingresso na escola, até os primeiros meses após a adaptação da criança. Existem ainda casos em que a inserção da pesquisa só pode acontecer após um evento (por exemplo, a repercussão no comportamento dos colegas na sala de aula, após o seqüestro de um membro da turma). Em casos de violência contra crianças, por exemplo, não é possível entrar em contato de maneira planejada com os participantes antes que ocorram os atos de violência. Os processos proximais anteriores a esse evento serão acessados retrospectivamente, através dos relatos das pessoas envolvidas.

Para que se estabeleça a Inserção Ecológica, é preciso estar engajado em uma mesma atividade, criar regularidade na interação do objeto de investigação com os pesquisadores de acordo com os objetivos da investigação. É necessário também buscar o significado dos objetos e símbolos do contexto e ter presente que os processos proximais serão cada vez mais complexos. Ao considerar os processos proximais como os principais motores do desenvolvimento humano, apenas o entendimento progressivo e mais complexo destas atividades proporcionará aos pesquisadores um maior entendimento do contexto e do tempo. É através dos processos proximais que a influência de todos os outros elementos (pessoa, contexto, tempo) se expressa para o pesquisador. Por isso, os processos proximais são a lente que permite o acesso aos dados de pesquisa.

A interação dos investigadores com o contexto de pesquisa permite a discussão dos significados atribuídos aos mesmos por cada integrante, possibilitando uma análise dos processos proximais dentro da própria equipe. Esta forma de trabalhar com a coleta de dados, não deixa de lado a importância do seu rigor, sistematização e consistência, que caracterizam a formalidade da coleta. No entanto, a interação, presente em investigações baseadas nos princípios descritos neste artigo, é marcada pela informalidade (característica do ambiente natural).

Bronfenbrenner (1979/1996) afirmava que a concepção ecológica de desenvolvimento-no-contexto tem implicações para o método e o planejamento de pesquisas. Inicialmente, postulava que uma investigação seria considerada válida se executada num ambiente natural, envolvendo objetos e atividades da vida cotidiana. Entretanto, ele mesmo faz uma auto-crítica, avaliando posteriormente tal definição como "simplista e insensata" (p. 23), passando a afirmar que a validade ecológica é a "extensão em que o meio ambiente experienciado pelos sujeitos em uma investigação científica tem as propriedades supostas ou presumidas pelo investigador" (p. 24). Acrescenta, ainda, que não é simplesmente o ambiente no qual a pesquisa é realizada que define sua validade ecológica. Esta se relaciona à interação dos pesquisadores com o contexto estudado. Para que se realize é necessário que a equipe de pesquisa se envolva com o contexto de investigação e capte como as pessoas percebem as interações entre elas e, portanto, como se estabelecem os processos proximais. Não é possível, portanto, perder de vista que as pessoas que ocupam o papel de pesquisadores também estão engajadas nesse processo, influenciando o desenvolvimento dos demais personagens e sendo por eles influenciados. Neste sentido, esse é um contraponto à neutralidade da ciência.

Através do conceito de validade ecológica, Bronfenbrenner (1979/1996) afirmava a necessidade de levar em conta o como a situação de pesquisa foi percebida e interpretada pelos participantes do estudo. Apesar desse conceito ter desaparecido dos estudos de Bronfenbrenner, a Inserção Ecológia faz uma retomada do mesmo, indicando-o como um dos objetivos a ser sempre atingidos quando se desenvolve uma pesquisa (Cecconello \& Koller, 2003). Utilizando as noções de pessoa, processo, contexto e tempo é possível o acesso ao movimento e ao desenvolvimento das pessoas inseridas em um determinado contexto de pesquisa. A preocupação com a acurácia que os pesquisadores fazem do campo é necessária para tentar atingir a validade ecológica dos achados. Assim, evita ao máximo a possibilidade de interpretações errôneas dos dados pelos pesquisadores e garante a validade ecológica do estudo. No entanto, a interpretação errônea dos pesquisadores também é dado a ser considerado nos resultados e diz respeito às peculiaridades e ao processo de desenvolvimento dos pesquisadores e de seus processos na inserção. $\mathrm{O}$ valor do campo fenomenológico na pesquisa ecológica enfatiza a forma como os participantes experienciam a situação de pesquisa no papel que desempenham. Apesar de indicar a importância deste construto, Bronfenbrenner reconheceu que "a validade ecológica é um objetivo a ser buscado, vislumbrado, mas nunca atingido" (p. 27). O objetivo dos pesquisadores deve ser, portanto, aproximar-se ao máximo desse ideal. Através da Inserção Ecológica, a equipe de pesquisa pode chegar o mais perto possível da obtenção de acurácia compartilhada dos achados, uma vez que devolve, no aconchego da percepção dos participantes, as suas impressões.

O conceito de validade ecológica está intimamente associado à Inserção Ecológica, tendo em vista que esse modelo visa ao acesso dos padrões de interação das pessoas (processos proximais) e à influência sobre a percepção e a interpretação do estudo pelos participantes. Padrões estes que só podem ser analisados se os pesquisadores permanecerem durante um período de tempo mínimo no campo. Apenas desta forma, os pesquisadores podem estar mais seguros quanto ao que estão compreendendo do ambiente e se essa compreensão se dá de maneira semelhante a como ele é experienciado pelos participantes da pesquisa. E mais ainda, poderão se assegurar que sua compreensão encontra guarida na percepção dos participantes, afirmado por eles mesmos.

Tipicamente, uma mudança no contexto indica alteração nas regras de uma interação. Onde a pessoa está, com quem e quando define as formas como interage com as outras e com símbolos e objetos que a cerca. Os comportamentos só fazem sentido se compreendidos no contexto no qual foram construídos. Modificações de contexto geram variações nas interações e nas formas como as pessoas se comunicam (Becvar \& Becvar, 1999). Transforma- 
ções nestas formas de comunicação e interação provocam alterações no contexto. Assim, há uma relação dinâmica entre as interações e os contextos (Bronfenbrenner \& Morris, 1998).

\section{Inserção Ecológica como Método em Investigação}

A seguir, apresentam-se quatro estudos (Cecconello, 2003; De Antoni, 2005; Morais, 2005; Neiva-Silva, 2003) desenvolvidos por pesquisadores do Centro de Estudos Psicológicos sobre Meninos e Meninas de Rua (CEP-RUA) da Universidade Federal do Rio Grande do Sul (UFRGS), que utilizaram este método em sua investigação. A apresentação destes estudos tem como finalidade discutir quais os pontos teórico-metodológicos relativos à Inserção Ecológica foram considerados em cada uma das investigações. A partir desta análise, será feita uma tentativa de constituir alguns critérios básicos para o estabelecimento da Inserção Ecológica.

Cecconello (2003), em seu estudo de doutorado, apresentou a Inserção Ecológica como seu método de pesquisa do desenvolvimento-no-contexto. Neste estudo, a inserção da equipe de pesquisa na comunidade abrangeu o acompanhamento de famílias em situação de risco pessoal e social por um período de quatro anos. Esta inserção iniciou-se ainda no mestrado da pesquisadora. A inserção incluiu visitas freqüentes, conversas informais e entrevistas com as famílias, marcadas pela organização e definição de objetivos da investigação. No entanto, a informalidade nas interações com os participantes da pesquisa também foi fundamental e esteve presente de forma marcante. Das 12 famílias participantes do estudo de mestrado, foram selecionadas três para o de doutorado. Foram realizadas entrevistas com as famílias no período de 1999 a 2002 sendo que, durante este período, houve pelo menos duas entrevistas formais com cada família por ano. Durante as entrevistas, dois pesquisadores estavam presentes, fato que tornava possível a observação de comportamentos não-verbais dos entrevistados e da movimentação no ambiente. Entre uma entrevista e outra, as famílias eram encontradas na comunidade, na escola, no centro comunitário, na rua, ou visitadas informalmente.

De acordo com Cecconello (2003), a investigação baseou-se na consecução de processos proximais tanto em relação aos participantes quanto para a equipe de pesquisa. As famílias, ao falarem sobre suas experiências de vida, tiveram a possibilidade de refletir e aprender com elas. A equipe, ao interagir com as famílias e a comunidade onde viviam, conseguiu captar unidades de sentido importantes para responder às questões de pesquisa e desenvolver novas hipóteses teóricas. A autora defende, no entanto, que os processos proximais (entre a equipe e as famílias) só foram possíveis devido à Inserção Ecológica (presença constante, significativa e estável) da equipe de pesquisa no contexto em estudo. A equipe precisou tornar-se parte do ambiente para adquirir a condição de estar inserida ecologicamente. Discussões ocorridas semanalmente entre os membros da equipe foram um fator importante para a sis- tematização dos dados, pois foi apenas através deste processo que as idéias sobre as famílias pesquisadas eram compartilhadas por eles e se tornavam mais claras. O modo como as entrevistas foram concluídas foi outro aspecto importante do trabalho de Cecconello. O encerramento das entrevistas com as famílias foi definido após a análise parcial das mesmas, na qual a equipe averiguava se todos os assuntos do roteiro haviam sido apreciados e se as histórias das famílias estavam coesas. Os membros da equipe, então, avisavam às famílias que o trabalho de pesquisa havia sido encerrado, realizando uma breve devolução. Algumas orientações já fornecidas pela equipe às famílias eram enfatizadas, destacando a relevância dos aspectos positivos apresentados pelas famílias. Finalmente, a equipe se colocava à disposição dos participantes, fornecendo números de telefones para eventuais encontros futuros. Visitas eventuais posteriores foram feitas, devido aos laços de amizade estabelecidos, bem como o acompanhamento em encaminhamentos realizados, mas este já não era mais o tempo da pesquisa.

Para realizar um estudo sobre as expectativas futuras de adolescentes em situação de rua, Neiva-Silva (2003) também utilizou a Inserção Ecológica no contexto da rua e das instituições freqüentadas por eles. O pesquisador considerou vários microssistemas nos quais eles circulavam, pois a relação estabelecida com cada um influenciava de maneira significativa na idealização do futuro destes jovens. Essa abordagem metodológica possibilitou a compreensão da complexidade do desenvolvimento destes adolescentes. Segundo Neiva-Silva, os dados obtidos durante a investigação dificilmente seriam conhecidos de outra maneira, pois a experiência de interação com os adolescentes nos seus próprios contextos permitiu o conhecimento profundo da temática de investigação proposta pelo estudo. Isso foi possível não só pelo contato direto com os participantes e seus contextos, mas porque o pesquisador estava atento aos significados que estes davam aos ambientes, objetos, pessoas e situações a sua volta. O pesquisador precisava "impregnar-se" da vida da rua, mantendo-se pesquisador, mas apropriando-se da "vida da rua" que é a experiência dos participantes que queria abordar. O pesquisador pretendia fazer parte do cenário dos participantes como um pesquisador.

Antes da realização da coleta dos dados propriamente dita (que será descrita a seguir), foi realizada, previamente, uma fase denominada "período de vinculação", que durou aproximadamente quatro meses. A duração desse período não foi pré-estipulada, mas o objetivo de criar vínculo com todos os participantes do estudo iria definir o tempo necessário para criar um ambiente favorável à pesquisa. O período de vinculação durou até o pesquisador perceber-se impregnado pela vida da rua dos meninos em estudo. Neste período, a equipe de pesquisa realizou visitas periódicas aos locais em que a presença dos adolescentes era mais freqüente. Também foram estabelecidas regras de convivência entre o pesquisador e os participantes, nos quais, por exemplo, o adolescente não poderia usar droga na presença da equipe de pesquisa. Após esta fase, o 
contato com os participantes ocorreu em quatro momentos distintos e configurou a coleta dos dados de forma mais sistemática. No primeiro momento, a pesquisa foi apresentada e foi realizada a fase inicial da entrevista, com cada menino individualmente. No seguinte, foi feita a entrega de uma máquina fotográfica e foram dadas orientações aos adolescentes quanto ao uso do equipamento e sobre a tarefa de fotografar espaços significativos para eles. No terceiro momento, a equipe recolheu o material fotográfico para revelação e marcou o quarto encontro, no qual foi realizada a segunda fase da entrevista com a discussão sobre as fotos de cada adolescente. A saída de campo do pesquisador foi lenta e acompanhada do monitoramento de encaminhamentos que haviam sido feitos. No entanto, o contrato do pesquisador com os participantes havia sido cumprido e este fato estava claro para eles. A devolução dos resultados de pesquisa foi dada também às instituições envolvidas, que permitiram acesso do pesquisador às suas dependências.

O estudo de doutorado desenvolvido por De Antoni (2005) utilizou a Inserção Ecológica em grupos familiares. A equipe de pesquisa permaneceu em contato com três instituições (um hospital, uma ONG e uma escola) que indicavam as famílias para estudo. Houve, portanto, uma preocupação em explorar diversos contextos nos quais as famílias se desenvolviam. A equipe de pesquisa, além de realizar entrevistas com as famílias participantes do estudo, participou de diversas atividades conforme o local de inserção das famílias. No hospital, participou da triagem de casos encaminhados para o ambulatório de violência e do acompanhamento das reuniões de discussão de casos. Na ONG, ministrou cursos de extensão e deu supervisão de casos em atendimento. $\mathrm{Na}$ escola, realizou oficinas com estudantes e palestras para os professores sobre temáticas demandadas por eles.

A equipe de pesquisa, como coleta de dados para o estudo, realizou as entrevistas e aplicação de um instrumento denominado Family System Test (FAST) na casa das famílias. Quando a ida até a casa não era possível, os contatos aconteceram nas instituições. Segundo De Antoni e Koller (2004), a Inserção Ecológica ocorreu pela possibilidade de interação entre pesquisadores, pesquisados, e as outras pessoas que estavam envolvidas com eles. As interações ocorreram em quatro níveis: intra-equipe de pesquisa, interequipes, entre equipes de pesquisa e grupos familiares, e intrafamiliares. Houve cuidado ao entrevistar as famílias, para que isto ocorresse somente após o esclarecimento do papel da equipe de pesquisa junto às instituições. Além disto, o uso dos dados foi previamente discutido e acordado com as famílias, evitando problemas com a confidencialidade ou com a necessidade de quebra de sigilo. Foram realizados cerca de cinco contatos com cada família.

Morais (2005), em seu estudo de mestrado, utilizou a Inserção Ecológica com o objetivo de investigar aspectos relacionados à saúde de crianças e adolescentes em situação de rua. A equipe inseriu-se em duas instituições de atendimento a essa população na cidade de Porto Alegre, antes do início da coleta propriamente dita. Desde esse momento, no entanto, as instituições foram informadas e concordaram com a inserção da equipe. Este período de estabelecimento de vínculos aconteceu durante três meses, com visitas às instituições ocorrendo, em média, duas vezes por semana. Para se integrar às instituições, os membros da equipe participavam de atividades rotineiras, tentando não interferir no cronograma de atividades destes locais. Além disso, produziam diários de campo para registrar impressões sobre os aspectos relacionados ao objetivo da pesquisa. Foram realizadas entrevistas tanto com os adolescentes atendidos, como com os profissionais das instituições, a fim de se obter um quadro mais completo da situação de saúde das crianças e adolescentes atendidos.

As entrevistas com os participantes da pesquisa ocorreram quando a equipe sentiu que o objetivo de vinculação havia sido alcançado. Foi realizada, também, a sistematização dos dados (formais e informais) sobre saúde observados nas instituições durante todo o período de inserção nas instituições. Nesse sentido, Morais (2005) destaca que tanto a realização das entrevistas com as crianças/adolescentes e profissionais quanto os momentos de conversa informais, participação nos grupos terapêuticos e atividades de lazer, registrados nos diários de campo, foram igualmente importantes para o processo de pesquisa. Várias vezes ao longo do processo de pesquisa, a equipe pôde acompanhar os adolescentes e profissionais das instituições em outros contextos, além daquele no qual estavam inseridos (visitas às casas das famílias das crianças e adolescentes, idas ao parque ou ao médico, por exemplo).

Outro ponto ressaltado por Morais (2005), ocorrido durante a inserção, é que havia reciprocidade nas relações. Os pesquisadores estavam atentos para o atendimento das necessidades dos participantes e puderam identificar trocas, pois as crianças e adolescentes manifestaram interesse em participar da pesquisa. Tal reciprocidade contribuiu para a qualidade do dado coletado, garantindo a sua validade ecológica.

\section{Análise de Pontos Comuns aos Estudos Utilizando a Inserção Ecológica}

O trabalho em equipes de pesquisa foi uma constante nos quatro estudos descritos na seção anterior. Cada um registrou suas próprias percepções e impressões através de diários de campo e nos relatos gerados com os dados da pesquisa. Cecconello (2003) e Morais (2005), por exemplo, pediram aos membros de suas equipes que confeccionassem textos, incorporados aos trabalhos acadêmicos apresentados, que descrevessem suas percepções da pesquisa, como pessoas em desenvolvimento. Estes e diversos olhares e relatos dos pesquisadores ao longo da apresentação dos resultados e da discussão permitiram o acesso às informações sobre os processos proximais que se estabeleciam no contexto. Essas informações foram valorizadas e utilizadas na compreensão dos dados, salientando, quando identificado pela equipe, que o resultado 
obtido encontrava suporte na observação sistemática do contexto, em uma conversa informal, no relato de algum membro da equipe e assim por diante.

Porém, para a busca da validade ecológica, foi importante a participação dos pesquisadores em diversas atividades e não somente na coleta de dados propriamente dita. Só assim, se estabeleceram diversas formas de acesso e confirmação dos dados coletados. As equipes integraramse em diversos espaços, acessaram seus dados através de vários recursos (entrevistas, observações, diários de campo, fotografias, e contatos informais) e interagiram com o ambiente, entrando em contato direto com o fenômeno investigado.

Ao estabelecerem um "período de vinculação" com as instituições (rua, escola, família, ONGs, etc.), os pesquisadores relatam apropriação do contexto e passam a fazer parte dele, porém com um papel muito bem definido, através da definição de objetivos claros no que se refere a sua atividade de investigação. Somente após um tempo envolvidos com uma instituição ou com várias, foi iniciado o processo de coleta e sistematização de dados. Além dos dados coletados no período de vinculação (através do diário de campo) foram utilizados outros recursos já conhecidos da pesquisa científica para a investigação específica da questão em estudo (testes, entrevistas, fotografias, por exemplo). Assim, a coleta não se resumiu a um único momento no qual os pesquisadores obtiveram seus dados através de instrumentos estruturados anteriores a ida à campo. Houve, assim, a combinação e a integração de diversas estratégias para a obtenção e para melhor se aproximar da validade ecológica dos dados. Na Inserção Ecológica, há uma combinação de estratégias mais flexíveis e informais, como as conversas espontâneas durante o período de vinculação, por exemplo, como estratégias mais rigorosas e formais, como o uso de testes psicológicos. Essa combinação permite que os pesquisadores entrem em contato com o ambiente estudado, de uma maneira menos artificial, garantindo contato mais próximo com os participantes. Fornecem, ao mesmo tempo, a possibilidade de obter dados seguros sobre o assunto investigado, que não seriam alcançados apenas com estratégias menos rigorosas ou mesmo com as mais tradicionais (sejam qualitativas ou quantitavas) isoladamente (por exemplo, o resultado de uma escala de avaliação psicológica descontextualizada). É identificado, portanto, a Teoria Bioecológica do Desenvolvimento Humano em todas as fases da pesquisa, desde a problematização até a apresentação e discussão de resultados. A leitura do campo em investigação é feita apoiada nesse referencial teórico, não podendo ser desconectados.

\section{Resumindo...}

A Inserção Ecológica, portanto, obedece a alguns pressupostos e critérios. Baseia-se na TBDH proposta por Bronfenbrenner (1979/1996; Bronfenbrenner \& Morris, 1998). É uma tentativa de operacionalização destes pressupostos na coleta e na análise dos dados obtidos em pes- quisas-no-contexto (Cecconello \& Koller, 2003). O processo de pesquisa propriamente dito ocorre após um período de vinculação da equipe de pesquisa com os participantes da pesquisa, inseridos no contexto de desenvolvimento destes participantes. Neste período, deve ser esclarecido o contrato para o desenvolvimento da pesquisa, tratando da permanência da equipe, da participação das pessoas, das atividades propostas, bem como da maneira que ocorrerá a saída da equipe do campo e a devolução dos dados. Todos estes aspectos precisam ser expressos e acordados no Termo de Consentimento Livre e Esclarecido. Na Inserção Ecológica é necessário também prever e informar que a equipe seja capaz de fornecer devoluções informais durante o andamento da pesquisa.

Como nesta proposta metodológica há sempre o envolvimento de uma equipe e não apenas de uma pessoa individualmente, é necessário que os membros sejam constantemente capacitados e supervisionados. Treinar e supervisionar a equipe é imprescindível para a garantia do rigor metodológico e dos procedimentos éticos. Para que uma boa preparação seja possível é indispensável o conhecimento aprofundado da Teoria Bioecológica do Desenvolvimento Humano e suas propostas para a pesquisa em psicologia. Os quatro componentes principais do modelo ecológico: processo, pessoa, contexto e tempo constituem a base para a Inserção Ecológica da equipe de pesquisa e para a compreensão do fenômeno estudado. $\mathrm{O}$ aspecto mais relevante, entretanto, deve ser a análise dos processos proximais, que ocorrem através da interação de pesquisadores, participantes, objetos e símbolos presentes nos diferentes níveis ambientais (micro ao macrossistema), a fim de discutir os achados da pesquisa.

Além do âmbito da interação dos pesquisadores e participantes, os processos proximais também devem ser investigados no contexto da equipe de pesquisa, tendo em vista que os pesquisadores também são pessoas em desenvolvimento e têm seus próprios contextos e histórias. Através da coleta de informações, percepções e sentimentos dos pesquisadores torna-se possível fazer uma análise dos processos proximais dentro da própria equipe. A entrada de uma equipe de pesquisa, e não apenas de um único pesquisador em campo, é um ponto importante por permitir acesso a dados não verbais (através de observação), a processos proximais em várias pessoas em desenvolvimento, diversidade de interpretação e análise dos dados. A discussão dos vários pontos de vista dos membros da equipe atua como facilitador para a busca da validade ecológica, evitando interpretações distantes das relacionadas ao foco das investigações ou das presentes nos contextos estudados. Diante disso, todas as compreensões geradas no contexto de pesquisa devem ser consideradas na análise dos dados.

A partir dos pontos em comum nos trabalhos descritos e discutidos, as condições mínimas para desenvolver pesquisas seguindo a Inserção Ecológica podem ser identificadas. A necessidade de melhor compreender esta proposta metodológica e dos critérios mínimos necessários para a sua utilização, no entanto, continua em voga. 
Trata-se de um método novo, e é importante a contínua atenção às pesquisas planejadas a partir dessa abordagem, para uma melhor sistematização dos procedimentos adotados. A pesquisa-no-contexto exige uma compreensão ecológica do evento estudado. Entretanto, a Inserção Ecológica pretende ir além desta, envolvendo outros elementos que potencializam a validade ecológica dos dados através do estabelecimento de processos proximais.

\section{Referências}

Becvar, D., \& Becvar, R. (1999). Systems theory and family therapy (2. ed.). Lanham, MD: University Press of America.

Bronfenbrenner, U. (1986). Ecology of the family a context for human development: Research perspectives. Developmental Psychology, 32(6), 723-742.

Bronfenbrenner, U. (1996). A ecologia do desenvolvimento humano: Experimentos naturais e planejados (M. A. V. Veronese, Trad.). Por to Alegre, RS: Artes Médicas (Original publicado em 1979)

Bronfenbrenner, U. (1999). Environments in developmental perspective: Theorical and operational models. In S. L. Friedmann \& T. D. Wacks (Eds.), Measuring environment across the life span: Emerging methods and concepts (pp. 3-30). Washington, DC: American Psychological Association.

Bronfenbrenner, U. (2005). The bioecological theory of human development. In U. Bronfenbrenner (Ed.), Making human beings human: Bioecological perspectives on human development (pp. 315). Thousand Oaks, CA: Sage Publications.

Bronfenbrenner, U., \& Ceci, S. J. (1994). Nature-nurture reconceptualized in developmental perspective: A bioecological model. Psychological Review, 101, 568-586.

Bronfenbrenner, U., \& Evans, G. (2000). Developmental science in the $21^{\text {st }}$ century: Emerging questions, theoretical models, research designs and empirical findings. Social Development, 9, 115-125.

Bronfenbrenner, U., \& Morris. P. A. (1998). The ecology of developmental processes. In W. Damon (Series Ed.) \& R. M. Lerner (Vol. Ed.), Handbook of child psychology: Vol. 1. Theoretical models of human development (pp. 993-1027). New York: John Wiley \& Sons.

Cairns, R. B., \& Cairns, B. (1995). Social ecology over time and space. In P. Moen, G. H. Elder Jr. \& K. Lüscher (Eds.), Examining lives in context (Vol. 1, pp. 397-421). Washington, DC: American Psychological Association.

Cecconello, A. M. (2003). Resiliência e vulnerabilidade em famílias em situação de risco. Tese de Doutorado não-publicada, Curso de Pós-Graduação em Psicologia do Desenvolvimento, Universidade Federal do Rio Grande do Sul, Porto Alegre, RS.

Cecconello, A. M., \& Koller, S. H. (2003). Inserção ecológica na comunidade: Uma proposta metodológica para o estudo de famílias em situação de risco. Psicologia: Reflexão e Crítica, 16(3), 515-524.

Copetti, F., \& Krebs, R. J. (2004). As propriedades da pessoa na perspectiva do paradigma bioecológico. In S. H. Koller (Ed.), Ecologia do desenvolvimento humano: Pesquisa e intervenção no Brasil (pp. 67-89). São Paulo, SP: Casa do Psicólogo.

De Antoni, C. (2005). Coesão e hierarquia em famílias com história de abuso fisico. Tese de Doutorado não-publicada, Curso de Pós-Graduação em Psicologia do Desenvolvimento, Universidade Federal do Rio Grande do Sul, Porto Alegre, RS.

De Antoni, C., \& Koller, S. H. (2004). A pesquisa ecológica sobre violência no microssistema familiar. In S. Koller (Eds.), Ecologia do desenvolvimento humano: Pesquisa e intervenção no Brasil (pp. 31 1-336). São Paulo, SP: Casa do Psicológo.
Elder, G. H., Jr. (1995). The importance of process. In P. Moen, G. H. Elder Jr. \& K. Lüscher (Eds.), Examining lives in context (Vol. 1, pp. 393-395). Washington, DC: American Psychological Association.

Magnusson, D. (1995). Individual development: A holistic, integrated, model. In P. Moen, G. H. Elder Jr. \& K. Liuscher (Eds.), Examining lives in context (Vol. 1, pp. 19-60). Washington, DC: American Psychological Association.

Morais, N. A. (2005). Saúde e doença em crianças e adolescentes em situação de rua: Concepções e experiência. Dissertação de Mestrado não-publicada, Curso de Pós-Graduação em Psicologia do Desenvolvimento, Universidade Federal do Rio Grande do Sul, Porto Alegre, RS.

Neiva-Silva, L. (2003). Expectativas futuras de adolescentes em situação de rua: Um estudo autofotográfico. Dissertação de Mestrado não-publicada, Curso de Pós-Graduação em Psicologia do Desenvolvimento, Universidade Federal do Rio Grande do Sul, Porto Alegre, RS. 